\title{
Aspectos florístico e estrutural de um fragmento de floresta com araucária utilizado para o pastoreio de bovinos
}

LUCIANO FARINHA WATZLAWICK

Rubens Marques Rondon Neto Marcos Viníius Winckler Caldeira

Emerson Roberto Schoeninger

\section{RESUMO}

O presente trabalho teve como objetivo conhecer, analisar e descrever a composição florística e a estrutura do componente arbóreo de um fragmento de Floresta Ombrófila Mista Montana, utilizado para o pastoreio de bovinos, localizado no município de Criúva - RS. Em 7 unidades amostrais de $10 \times 100 \mathrm{~m}$ foram inventariados 533 indivíduos com DAP ${ }^{3} 10 \mathrm{~cm}$, pertencentes a 20 famílias, distribuidas em 38 espécies e 33 gêneros. As famílias que tiveram os maiores números de indivíduos amostrados foram: Myrtaceae (33,0 $\%)$, Euphorbiaceae (19,7\%) e Araucariaceae (17,4\%). A densidade total estimada foi de 761,4 indivíduos/ha e os valores médios de DAP e altura encontrados foram $22,9 \mathrm{~cm}$ e $9,7 \mathrm{~m}$, respectivamente. $O$ fragmento de floresta se caracteriza por não possuir sub-bosque, talvez devido a intensa presença do gado, que danifica os indivíduos de menor porte em diâmetro e altura. Portanto, existe o risco de não existir por algum tempo indivíduos prontos para ocupar os espaços deixados pela ausência dos indivíduos dominantes da floresta.

Palavras-chave: Fragmento florestal, Floresta com Araucária, Floresta Ombrófila Mista, 


\section{ABSTRACT}

The aim of this paper was to know, analyze and describe the floristic composition of the shrub and tree component and the structure of a Montane Mixed Ombrophylous Forest Fragment, used for bovines pasturage, in the municipal district of Criúva - RS. It was inventoried 533 individuous in seven $10 \times 100$ m plots with $\mathrm{DBH}^{3} 10$ $\mathrm{cm}$, distributed in 38 species from 33 gender and 20 families. The families wich presented the widest number of individuous were: Myrtaceae (33,0 \%), Euphorbiaceae (19,7\%) e Araucariaceae (17,4 $\%)$. The total density found was 761,4 individuous/ha, and the medium $\mathrm{DBH}$ is $22,9 \mathrm{~cm}$ and the higest $9,7 \mathrm{~m}$. The part of the forest investigated is characterized by the lack of understorey, probably caused by intense presence of cattle, damaging especially plants of minor height and diameter. This fact might explain the lack of individuals to occupy the gaps caused by the removal of dominant trees out of the forest.

Key words: fragment forest, Araucarian Forest, Mixed Ombrophylous Forest.

\section{INTRODUÇÃO}

O Inventário Florestal Contínuo do Rio Grande do Sul indica um aumento da cobertura florestal natural do estado de 5,62 $\%$ para $17,53 \%$, desde 1983 . Tem-se $38.159,52 \mathrm{~km}^{2}$ de floresta em estágio médio e avançado de sucessão e 11.396,77 km² em estágio inicial. O aumento da área de floresta nativa se deve ao abandono das áreas difíceis de serem cultivadas, principalmente em regiões serranas (REVISTA DA MADEIRA, 2001).

Dentre várias tipologias florestais existentes no Estado do Rio Grande do Sul, têm-se a Floresta Ombrófila Mista, também conhecida como Floresta com Araucária, em vários estágios sucessionais. Conforme SOLÓRZANO-FILHO e KRAUS (2000), a ação humana levou a fragmentação e brusca redução da área ocupada por essa formação florestal. Em 1980, esta área foi estimada em apenas $5.654 \mathrm{~km}^{2}$ no Brasil, representando no final do século XX somente $3,1 \%$ de sua área original.

Para que haja um aproveitamento racional e sobrevivência das florestas é necessária aplicação de técnicas silviculturais adequadas, baseadas na ecologia de cada tipologia florestal. Para a aplicação de técnicas corretas de manejo florestal e assim obter o 
aproveitamento permanente, deve-se conhecer sua composição e estrutura. Os resultados das análises estruturais permitem fazer deduções sobre as origens, características ecológicas e sinecológicas, dinamismo e tendências do futuro desenvolvimento das florestas (HOSOKAWA et al., 1998).

Dentro desse contexto, o presente trabalho foi realizado em um fragmento de Floresta Ombrófila Mista Montana, utilizado para o pastoreio de animais, com o propósito de conhecer, analisar e descrever a florística e a estrutura da comunidade arbustivo-arbórea.

\section{MATERIAL E MÉTODOS}

O presente trabalho foi realizado em um fragmento de Floresta Ombrófila Mista Montana, com cerca de 8,5 ha, situado no município de Criúva - RS, entre as coordenadas geográficas $29^{\circ} 00^{\prime} 00^{\prime \prime}$ e $29^{\circ} 00^{\prime} 05^{\prime \prime}$ S e $50^{\circ} 55^{\prime} 49^{\prime \prime}$ e $50^{\circ} 56^{\prime} 27^{\prime \prime}$ W, com uma altitude média de 860 metros (Figura 1). No passado recente, essa vegetação sofreu cortes seletivos, voltados para a exploração do pinheiro (Araucaria angustifolia), do cedro (Cedrela fissilis) e de outras espécies fornecedoras de madeiras nobres. A área é utilizada para o pastoreio de bovinos desde o início da colonização.
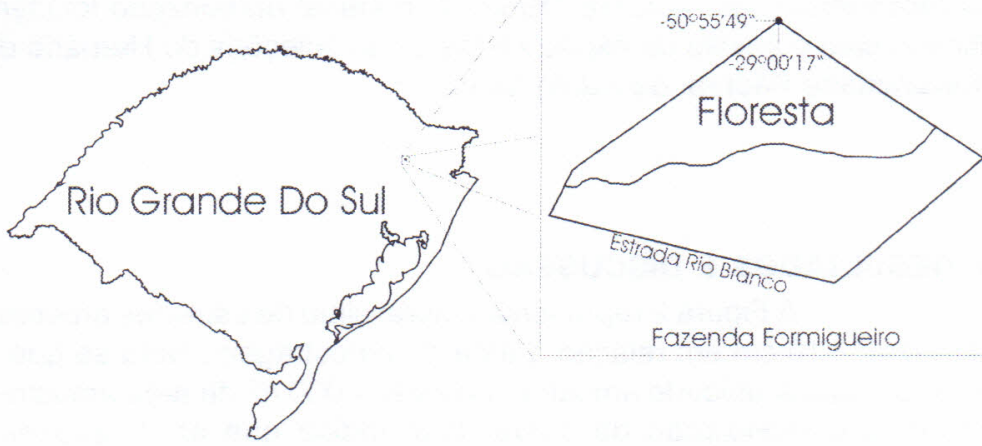

Fazenda Formigueiro

Fig. 1. Mapa de localização do fragmento de Floresta Ombrófila Mista Montana, em Criúva - RS. 
Pela classificação de Köppen, o clima da região é do tipo $\mathrm{Cfb}$, com temperatura média anual variando de $15,9^{\circ} \mathrm{C}$ a 16,6 ${ }^{\circ} \mathrm{C}$. Apresenta uma precipitação média anual de $1.826 \mathrm{~mm}$, podendo ocorrer geadas entre os meses de março a novembro (MORENO, 1961). O solo da região pertence à Unidade de Mapeamento Farroupilha. Os solos dessa unidade são desenvolvidos a partir de basaltos, profundos, moderamente drenados e possuem textura argilosa. Apresentam teores elevados de matéria orgânica, em torno de $6,5 \%$ na camada superficial. Também são fortemente ácidos com $\mathrm{pH}$ em água variando de 4,3 no horizonte superficial a 5,0 no mais profundo (EMBRAPA, 1973).

Para o levantamento dos indivíduos arbóreos com DAP $310 \mathrm{~cm}$, foram estabelecidas 7 unidades amostrais de $10 \times 100 \mathrm{~m}$ $\left(1000 \mathrm{~m}^{2}\right)$, distribuídas de forma aleatória. Todos os indivíduos amostrados foram identificados pelo nome vulgar e tiveram anotados o DAP, altura comercial altura total e posição sociológica, baseada na classificação de Kraft com modificação (dominante, codominante, dominada e oprimida).

De posse desses dados foram estimados os parâmetros estruturais para a descrição da estrutura horizontal da comunidade, os quais se encontram definidos nos trabalhos de LAMPRECHT (1964); MATTEUCCI e COLMA (1982); KENT e COKER (1992). Para a estimação destes parâmetros utilizou-se o Programa Fitopac 1 SHEPHERD (1994).

Todas as espécies amostradas no estudo tiveram seu material vegetativo coletado e, quando possível, o material reprodutivo, para serem submetidos aos processos de herborização, seguindo as recomendações do IBGE (1992). O material herborizado foi identificado com o auxílio de especialistas e das coleções do Herbário da Universidade Federal de Santa Maria.

\section{RESULTADOS E DISCUSSÃO}

A Figura 2 representa o acréscimo de espécies arbóreas com DAP $310 \mathrm{~cm}$ em relação à área de amostragem. Nota-se que a partir da quarta unidade amostral, ou seja, $4.000 \mathrm{~m}^{2}$ de área amostral, ocorre a estabilização da curva. Isso indica que as 7 unidades amostrais foram suficientes para caracterizar a vegetação em estudo, em termos de composição de espécies arbóreas. No município de São João do Triunfo - PR, DURIGAN (1999) também verificou a 
estabilização da curva espécie área em $4.000 \mathrm{~m}^{2}$, amostrando árvores com DAP $310 \mathrm{~cm}$.

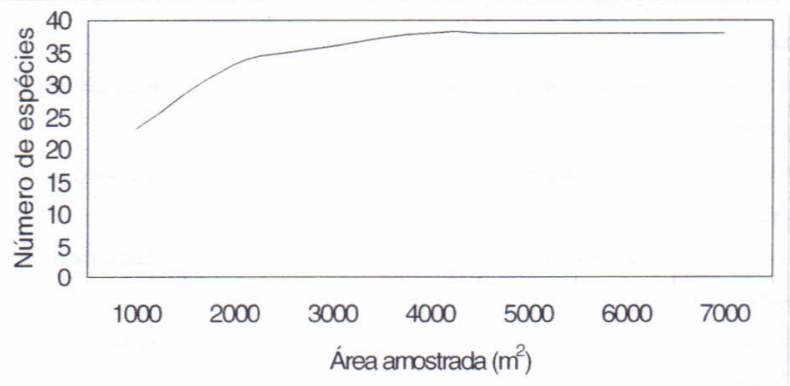

Fig 2: Curva do número de espécies/área, para verificação da suficiência amostral em um fragmento de Floresta Ombrófila Mista Montana, em Criúva - RS.

Na Tabela 1 estão relacionadas as espécies em ordem alfabética de famílias e gêneros, seguidas dos nomes vulgares. Foram inventariados 533 indivíduos, pertencentes a 38 espécies que se encontram distribuídas em 20 famílias botânicas e 33 gêneros. As famílias que tiveram maior riqueza de espécies foram: Myrtaceae (10); Lauraceae (4); Sapindaceae (3); Euphorbiaceae, Rhamnaceae e Rutaceae (2) e 15 famílias representadas por apenas uma espécie. Resultados semelhantes foram encontrados por NEGRELLE e SILVA (1992), no município de Caçador - SC, onde verificaram a presença de 43 espécies com DAP ${ }^{3} 5 \mathrm{~cm}$, distribuídas em 28 famílias e 39 gêneros.

Tabela 1: Relação das espécies arbóreas amostradas em um fragmento de Floresta Ombrófila Mista Montana, localizado em Criúva RS.

\begin{tabular}{ll}
\hline Familia / Nome Científico & Nome Vulgar \\
\hline Anacardiaceae & \\
$\quad$ Lithraea brasilliensis L. Marchand & Aroeira-braba, bugreiro \\
$\begin{array}{l}\text { Annonaceae } \\
\text { Rollinia rugulosa Schltdl. }\end{array}$ & Araticum \\
Aquifoliaceae & \\
$\quad$ Ilex brevicuspis Reissek & Caúna, caúna-da-serra \\
\hline
\end{tabular}

...Continua... 
Tab. 1 continuação ....

\section{Araucariaceae}

Araucaria angustifolia (Bert.) Kuntze

Pinheiro-brasileiro

\section{Asteraceae}

Dasyphyllum spinescens (Leiss.) Cabrera

Açucará, sucará

\section{Bignoniaceae}

Tabebuia alba (Cham.) Sandwith

Ipê-ouro, ipê-branco,

\section{Cunoniaceae}

Lamanonia speciosa (Camb.) L. B. Smith

Guaraperê

\section{Cyatheaceae}

Alsophila sp.

Xaxim

\section{Euphorbiaceae}

Sapium glandulatum (Vell.) Pax.

Leiteiro, pau-leiteiro

Sebastiana commersoniana (Baill.)L. B. Smith \& R. J. Downs

Branquilho, branquinho

\section{Flacourtiaceae}

Banara parviflora (A. Gray) Bentham

Guaçatunga-preta

\section{Lauraceae}

Cinnamomum glaziovii (Mez) Kosterm.

Nectandra lanceolata Ness et Mart. ex Ness

Nectandra megapotonica (Spreng.) Mez

Ocotea pulchella (A. Rich.)Ness

\section{Myrsinaceae}

Myrsine coriacea (Sw.) R. Br.

\section{Myrtaceae}

Blepharocalyx salicifolius (Kunth) O. Berg

Compomanesia xanthocarpa O. Berg

Eugenia involucrata DC.

Eugenia pluriflora DC.

Acca sellowiana (O. Berg) Burret

Myrcia bombycina (O. Berg) Nied.

Myrcia sp.

Myrcianthes gigantea (D. Legrand) D. Legrand

Myrcianthes pungens (O. Berg.) D. Legrand

Siphoneugena reitzi $\mathrm{D}$. Legrand

\section{Rhamnaceae}

Hovenia dulcis Thunberg.

Scutia buxifolia Reissek

Uva-do-japão

Coronilha

Canela-papagai

Canela-amarela

Canela-preta

Canela-lageana

Capororoquinha

Murta

Guabirobeira-do-mato

Cerejeira-do-mato

Jaboticabeira

Goiabeira-serrana

Guamirim-do-campo

Guamirim-branco

Araçá, araçá-do-mato

Guabiju, guabiraguaçu

Camboim, cambuim

82 Ciência \& Natura, Santa Maria, 24: 77 - 90, 2002. 
Tab. 1 continuação...

\begin{tabular}{ll}
\hline Rosaceae & \\
Prunus sellowi Koehne & Pessegueiro-do-mato \\
Rutaceae & \\
Zanthoxylum hyemale A. St. Hil. & Cüentrilho \\
Zanthoxylum rhoifolioum L. & Mamica-de-cadela \\
Sapindaceae & \\
Allophylus edulis (A. St. Hil. et al.) Raldk. & Chal-chal \\
Allophylus guaraniticus Camb. & Vacum, fruto-de-pombo \\
Cupania vernalis Cambess. & Camboata-vermelho \\
Matayba elaeagnoides Radlk. & Camboatá-branco \\
Solanaceae & \\
Cestrum calycinum Willd. & Coerana \\
Styracaceae & \\
Styrax leprosus Hook. et Arn. & Carne-de-vaca \\
Symplocace ae & \\
Symplocos uniflora (Pohl) Bentham & Sete-sangria, caujuja \\
\hline
\end{tabular}

As familias que tiveram maiores porcentagens do número de indivíduos amostrados foram: Myrtaceae $(33,0 \%)$, Euphorbiaceae $(19,7 \%)$ e Araucariaceae (17,4 \%). Juntas essas famílias representam $70,2 \%$ do número total de indivíduos amostrados. Em uma floresta semidevastada da região metropolitana do município de Curitiba - PR, KOEHLER et al. (1998) observaram que as famílias Myrtaceae, Lauraceae e Aquifoliaceae, representavam respectivamente $26,6 \%, 21,4 \%$ e $12,3 \%$ do total de indivíduos amostrados.

O DAP médio da comunidade arbórea foi estimado em $22,9 \mathrm{~cm}$, sendo que cerca de $82,5 \%$ do total de indivíduos amostrados possuem DAP maior que $10 \mathrm{~cm}$ e menor que $20 \mathrm{~cm}$ (Figura 3). Resultados parecidos foram obtidos por OLIVEIRA e ROTTA (1982), em uma floresta intensamente explorada situada em Colombo - PR, onde verificaram que $82,8 \%$ dos indivíduos tinham entre 5 a $25 \mathrm{~cm}$ de DAP. Acredita-se que devido às aberturas de copas provocadas pelas extrações de madeira que ocorreram no passado recente, favoreceram o ingresso e o crescimento dos indivíduos pertencentes. 


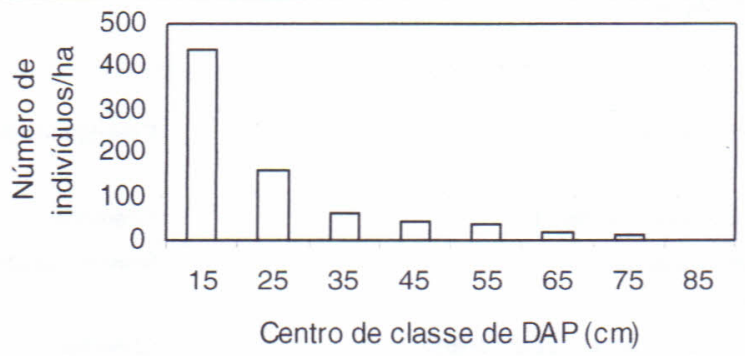

Fig. 3: Distribuição diamétrica por classe de diâmetro dos indivíduos arbóreos, amostrados em um fragmento de Floresta Ombrófila Mista Montana, em Criúva - RS.

A comunidade têm a presença da Araucaria angustifolia formando o dossel da floresta de forma bem distribuídas pela área do fragmento. O valor médio estimados para a altura total dos indivíduos amostrados com DAP ${ }^{3} 10 \mathrm{~cm}$ é de $9,7 \mathrm{~m}$. Por meio de observações de campo e comprovada na Figura 4, notou-se que a maioria dos indivíduos mensurados, isto é, cerca de $78,8 \%$, possuem uma altura total entre 7 a $11 \mathrm{~m}$, enquanto $28,1 \%$ e $36,0 \%$ dos indivíduos são $£ 7 \mathrm{~m} \mathrm{e}^{3} 11 \mathrm{~m}$, respectivamente. Portanto, percebe-se que a distribuição de altura da floresta não segue uma distribuição regular, ou seja, típica de florestas multiâneas. Verifica-se uma escassez de indivíduos nas classes inferiores e maiores concentrações nas intermediárias e superiores, talvez devido a ação destrutiva dos indivíduos de menor porte proporcionada pelos animais. Em caso de continuação da atividade de pastoreio no fragmento de floresta, percebese que não existe garantia de que o processo dinâmico da floresta se perpetue, pois são poucas as "arvores de reposição", que na ausência dos indivíduos dominantes poderá ocupar tal espaço.

Ao analisar a Figura 5, observa-se que $41 \%$ dos indivíduos são codominantes e $20 \%$ dominantes, totalizando $61 \%$ do total de indivíduos amostrados. Os demais indivíduos, ou seja, aproximadamente $39 \%$, tem-se $38 \%$ de dominados e $1 \%$ oprimidos. Tal fato pode ser atribuído a intensa presença do gado na vegetação, o qual danifica os indivíduos de menor porte em diâmetro e altura. Os impactos negativos do pastoreio de bovinos sobre florestas são relatados por SCHNEIDER et al. (1978), onde o constante pisoteio pode provocar acentuado desnudamento da superfície do solo; causam 
lesões mecânicas nas árvores, prejudica a regeneração natural, danifica as raízes superficiais responsáveis pela absorção de nutrientes e em conseqüência as árvores não se desenvolvem normalmente.

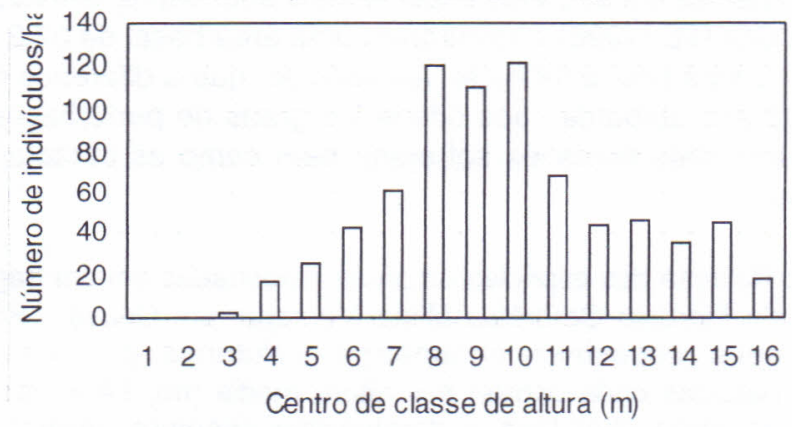

Fig. 4: Distribuição do número de indivíduos arbóreos por classes de altura, amostrados em um fragmento de Floresta Ombrófila Mista Montana, em Criúva - RS.

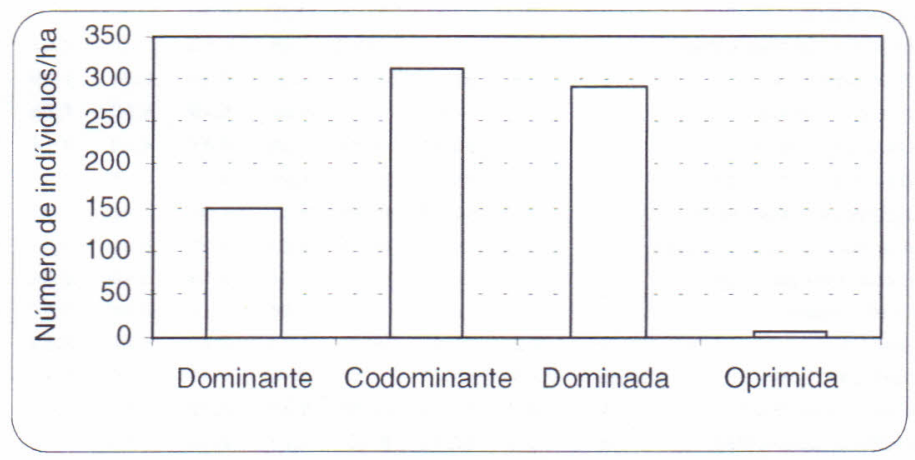

Fig. 5: Distribuição da posição sociológica dos indivíduos arbóreos, amostrados em um fragmento de Floresta Ombrófila Mista Montana, em Criúva - RS.

As espécies Araucaria angustifolia, Sebastiania commersoniana, Compomanesia xanthocarpa, Ilex brevicuspis, Myrcia bombycina e Nectandra megapotonica, estiveram presentes em todas unidades amostrais, portanto, são as espécies mais freqüentes da comunidade. Tais espécies contribuíram com 31,1\% da freqüência relativa total. Os resultados dos parâmetros 
fitossociológicos constam na Tabela 2 em ordem do valor de importância (VI) das espécies.

A Araucaria angustifolia contribuiu com cerca de 49,1 $\%$ da área basal total, pois além de apresentar maior porte que as demais espécies é a segunda espécie mais abundante. SANQUETTA e DALLA CORTE (1998) encontraram uma área basal de $37,2 \mathrm{~m}^{2} / \mathrm{ha}$, em uma floresta pouco alterada. Acredita-se, que a diferença desses resultados são atribuídas aos diferentes graus de perturbações que ambas formações florestais sofreram, bem como as características dos sítios.

Tabela 2: Relação das espécies arbóreas amostradas em um fragmento de Floresta Ombrófila Mista Montana, em Criúva - RS, com seus respectivos parâmetros estruturais: $p=$ número de parcelas onde ocorre; $h=$ altura média $(m) ; F A=$ freqüência absoluta (\%); DoA = dominância absoluta $\left(\mathrm{m}^{2} / \mathrm{ha}\right) ; \mathrm{DA}=$ densidade absoluta (indivíduos/ha); FR = freqüência relativa $(\%) ; \mathrm{DoR}=$ dominância relativa $(\%) ; \mathrm{DR}=$ densidade relativa $(\%)$ e VI = valor de importância (\%).

\begin{tabular}{|c|c|c|c|c|c|c|c|c|c|}
\hline Espécie & $\mathrm{p}$ & h & FA & DA & DOA & FR & DR & DoR & IVI \\
\hline Araucaria angustifolia & 7 & 13,3 & 100 & 132,90 & 21,62 & 5,19 & 17,45 & 49,13 & 71,76 \\
\hline Sebastiana commersoniana & 7 & 9,3 & 100 & 138,60 & 3,98 & 5.19 & 18,20 & 9,04 & 32,42 \\
\hline Siphoneugena reitzii & 6 & 7,8 & 85,71 & 52,90 & 0,87 & 4,44 & 6,94 & 1,99 & 13,37 \\
\hline Myrcia bombycina & 7 & 7,1 & 100 & 45,70 & 0,82 & 5,19 & 6,00 & 1,86 & 13,05 \\
\hline Lithraea brasilliensis & 6 & 8,7 & 85,71 & 35,70 & 1,38 & 4,44 & 4,69 & 3,14 & 12,27 \\
\hline Blepharocalyx salicifolius & 6 & 10,6 & 85,71 & 37,10 & 1,29 & 4,44 & 4,88 & 2,93 & 12,25 \\
\hline Dasyphyllum spinescens & 4 & 9,3 & 57,14 & 32,90 & 2,17 & 2,96 & 4,32 & 4,93 & 12,21 \\
\hline Compomanesia xanthocarpa & 7 & 8,2 & 100 & 34,30 & 1,04 & 5,19 & 4,50 & 2,37 & 12,06 \\
\hline Nectandra megapotonica & 7 & 10.6 & 100 & 27,10 & 1.34 & 5,19 & 3,56 & 3,04 & 11,79 \\
\hline llex brevicuspis & 7 & 11,5 & 100 & 15,70 & 1,84 & 5,19 & 2,06 & 4,17 & 11,42 \\
\hline Myrcia sp. & 5 & 8,2 & 71,43 & 38,60 & 1,14 & 3,70 & 5,07 & 2,59 & 11,36 \\
\hline Banara parviflora & 6 & 7,9 & 85,71 & 25,70 & 0,42 & 4,44 & 3,38 & 0,96 & 8,78 \\
\hline Sapium glandulatum & 4 & 12,4 & 57,14 & 11,40 & 0,79 & 2,96 & 1,50 & 1,81 & 6,27 \\
\hline Matayba elaeagnoides & 4 & 10,0 & 57.14 & 8,60 & 0.77 & 2,96 & 1.13 & 1.75 & 5.84 \\
\hline Myrcianthes gigantea & 5 & 8,9 & 71,43 & 11,40 & 0,24 & 3,70 & 1,50 & 0.54 & 5,74 \\
\hline Symplocos unifiora & 4 & 6,9 & 57,14 & 15,70 & 0,30 & 2,96 & 2,06 & 0,69 & 5.72 \\
\hline Eugenia pluriflora & 4 & 8,7 & 57,14 & 14,30 & 0,21 & 2,96 & 1,88 & 0,47 & 5,31 \\
\hline Cupania vernalis & 3 & 12,1 & 42,86 & 5,70 & 0,91 & 2,22 & 0,75 & 2,06 & 5,03 \\
\hline Espécie & $p$ & h & FA & DA & DoA & FR & DR & DoR & $|V|$ \\
\hline Ocotea pulchella & 4 & 9,8 & 57,14 & 7,10 & 0,24 & 2,96 & 0,94 & 0.54 & 4,44 \\
\hline Myrsine coriacea & 4 & 9,1 & 57,14 & 7,10 & 0,16 & 2,96 & 0,94 & 0,37 & 4,27 \\
\hline Myrcianthes pungens & 3 & 7,1 & 42,86 & 10,00 & 0,14 & 2,22 & 1,31 & 0,32 & 3,85 \\
\hline Lamanonia speciosa & 2 & 13,8 & 28,57 & 4,30 & 0,63 & 1,48 & 0,56 & 1,42 & 3,47 \\
\hline Scutia buxifolia & 3 & 9,9 & 42,86 & 5,70 & 0,10 & 2,22 & 0,75 & 0,23 & 3,2 \\
\hline Zanthoxylum rhoifolioum & 2 & 8,1 & 28,57 & 8,60 & 0,14 & 1,48 & 1,13 & 0,31 & 2,92 \\
\hline
\end{tabular}

86 Ciência \& Natura, Santa Maria, 24: 77 - 90, 2002. 
Tab. 2: continuação...

\begin{tabular}{lccccccccc}
\hline Tabebuia alba & 2 & 12,7 & 28,57 & 4,30 & 0,24 & 1,48 & 0,56 & 0,55 & 2,59 \\
Nectandra lanceolata & 1 & 13,3 & 14,29 & 2,90 & 0,61 & 0,74 & 0,38 & 1,40 & 2,51 \\
Eugenia involucrata & 2 & 8,5 & 28,57 & 4,30 & 0,15 & 1,48 & 0,56 & 0,34 & 2,38 \\
Prunus sellowii & 2 & 8,8 & 28,57 & 2,90 & 0,09 & 1,48 & 0,38 & 0,21 & 2,07 \\
Cestrum calycinum & 2 & 4,8 & 28,57 & 2,90 & 0,05 & 1,48 & 0,38 & 0,12 & 1,98 \\
Allophylus guaraniticus & 1 & 8,3 & 14,29 & 4,30 & 0,06 & 0,74 & 0,56 & 0,13 & 1,44 \\
Acca sellowiana & 1 & 4,2 & 14,29 & 2,90 & 0,02 & 0,74 & 0,38 & 0,05 & 1,17 \\
Styrax leprosus & 1 & 8,5 & 14,29 & 1,40 & 0,08 & 0,74 & 0,19 & 0,17 & 1,1 \\
Alsophila sp. & 1 & 2,5 & 14,29 & 1,40 & 0,05 & 0,74 & 0,19 & 0,11 & 1,03 \\
Hovenia dulcis & 1 & 12,0 & 14,29 & 1,40 & 0,04 & 0,74 & 0,19 & 0,10 & 1,02 \\
Zanthoxylum hyemale & 1 & 6,5 & 14,29 & 1,40 & 0,04 & 0,74 & 0,19 & 0,09 & 1,02 \\
Cinnamomum glaziovii & 1 & 8,0 & 14,29 & 1,40 & 0,02 & 0,74 & 0,19 & 0,04 & 0,97 \\
Allophylus edulis & 1 & 7,5 & 14,29 & 1,40 & 0,01 & 0,74 & 0,19 & 0,03 & 0,95 \\
Rollinia rugulosa & 1 & 5,0 & 14,29 & 1,40 & 0,01 & 0,74 & 0,19 & 0,02 & 0,95 \\
\hline Total & - & - & 1928,6 & 761,4 & 44,0 & 100 & 100 & 100 & 300 \\
\hline
\end{tabular}

A abundância total de 761,4 indivíduos/ha estimada para a comunidade arbórea foi baixa, quando comparada com outros resultados obtidos em Florestas com Araucária perturbadas (OLIVEIRA e ROTTA, 1982; KOEHLER et al., 1998). Isto pode ser explicado pela escolha do DAP mínimo ser menor $(5 \mathrm{~cm})$, o que acarreta numa maior inclusão de indivíduos, além dos diferentes graus de perturbações ocorridos nas florestas.

As dez espécies mais abundantes e seus respectivos número de indivíduos/ha foram: Sebastiania commersoniana $(138,6)$, Araucaria angustifolia $(132,9)$, Siphoneugena reitzii $(52,9)$, Myrcia bombycina $(45,7)$, Myrcia sp. $(38,6)$, Lithraea brasilliensis $(35,7)$, Blepharocalyx salicifolius $(37,1)$, Compomanesia xanthocarpa $(34,3)$, Dasyphyllum spinescens $(32,9)$ e Nectandra megapotonica $(27,1)$. Juntas essas espécies contribuíram com $75,6 \%$ do número total de árvores mensuradas. A abundância de Araucaria angustifolia foi superior aos encontrados por LONGHI (1980) e JARENKOW e BAPTISTA (1985), de 98,5 e 45,8 indivíduos/ha, respectivamente.

$\mathrm{Na}$ Figura 6 pode ser observado as dez espécies que apresentaram os maiores valores de VI. As espécies são também as mesmas mais abundantes, com exceção de llex brevicuspis que cedeu o lugar para Myrcia sp.. Juntas contribuíram com 67,5\% do VI total. A Araucaria angustifolia representa $23,9 \%$ do VI total, com grande contribuição do parâmetro dominância.

Pela classificação de KLEIN (1979) quanto ao habitat das espécies, verifica-se que 32 espécies por excelência se situa na mata primária bem desenvolvida, podendo ser encontradas em capoeiras e capoeirões. Nesse grupo estão inseridas oito espécies de 
maior VI. Para completar as dez espécies de maior VI, tem-se Dasyphyllum spinescens e Lithraea brasilliensis, que preferem vegetações secundárias e são heliófitas ou de luz difusa, podendo ser encontradas no interior da floresta primária, onde são bem menos freqüentes e expressivas. Myrsine coriaceae e Sapium glandulatum também se encaixam nesse grupo. A única espécie encontrada que prefere as bordas da floresta e clareiras foi Symplocos uniflora. E, como espécie exótica, apareceu somente Hovenia dulcis. Analisando pelo habitat preferido das espécies presentes e levantadas na área de estudo, suspeita-se de se tratar de um fragmento de floresta com características florísticas próximas de vegetação primária, entretanto, os cortes seletivos e o pastoreio do gado proporcionaram mudanças na estrutura e florística da floresta, principalmente nos indivíduos de menor porte que compõem os estratos inferior e intermediário da floresta.

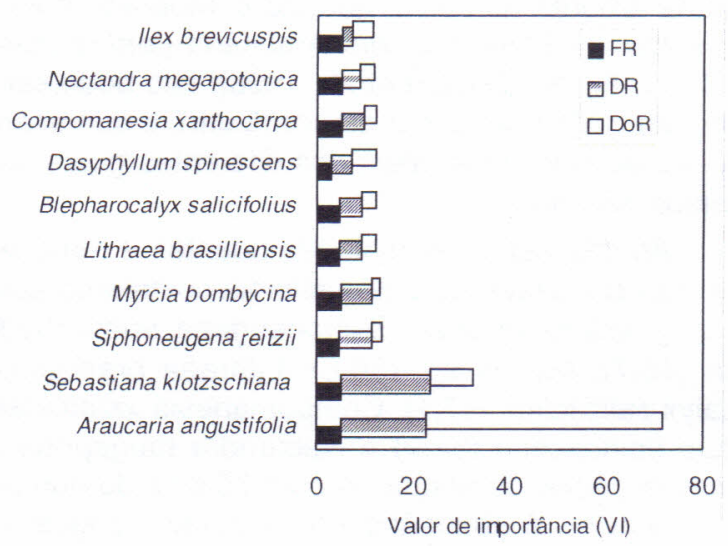

Fig. 6: Distribuição do VI das 10 principais espécies arbóreas de um fragmento de Floresta Ombrófila Mista Montana, em Criúva - RS.

\section{CONCLUSÃO}

A estrutura do fragmento da floresta se encontra descaracterizada devido principalmente ao pastoreio de animais no seu interior. Caso essa prática continuar, o processo de dinâmica da vegetação pode ficar comprometida, pois os indivíduos pertencentes às classes de menores diâmetros necessitam de condições favoráveis para o seu pleno desenvolvimento. Portanto, deve-se adotar práticas de manejo dos animais que vise a diminuição dos impactos provocados pelo pastoreio à floresta. 


\section{REFERÊNCIAS BIBLIOGRÁFICAS}

DURIGAN, M.E. Florística, dinâmica e análise proteica de uma Floresta Ombrófila Mista em São João do Triunfo - PR. Curitiba: UFPR, 1999. 125p. (Dissertação de Mestrado em Engenharia Florestal - Universidade Federal do Paraná).

EMBRAPA - Empresa Brasileira de Pesquisa Agropecuária. Levantamento de reconhecimento dos solos do Estado do Rio Grande do Sul. Recife: Ministério da Agricultura, 1973. 431p. (Boletim Técnico, 30).

HOSOKAWA, R.T.; MOURA, J.B.; CUNHA, U.S. Introdução ao manejo e economia de florestas. Curitiba: EdUFPR, 1998. 162p. IBGE - Fundação Instituto Brasileiro de Geografia e Estatística. Manual técnico da vegetação brasileira. Rio de Janeiro: IBGE, 1992. 132p. JARENKOW, J. A.; BAPTISTA, L.R.M. Composição florística e estrutura da Mata com Araucária na Estação Ecológica de Aracuri, Esmeralda, RS. Napaea, n.3, p.9-18, 1987.

KENT, M.; COKER, P. Vegetation description and analysis: a practical approach. London, Blackwell, 1992. 363p.

KLEIN, R.M. Ecologia da flora e vegetação do Vale do Itajaí. Sellowia, Itajai, n.31, p.103-164, 1979.

KOEHLER, A.; PÉlLICO-NETTO, S.; SANQUETTA, C.R. Análise da estrutura de uma Floresta Ombrófila Mista semidevastada, Fazenda Gralha Azul, Região Metropolitana de Curitiba, com implicações ao manejo. Rev. Acadêmica, Curitiba, n.1, p.37-60, 1998.

LAMPRECHT, H. Ensayo sobre la estrutura flotistica de la parte sur - oriental del bosque universitario "El Caimital", Estado Barinas. Rev. For. Venezolana, Mérida, v.7, n.10/11, p.77-119, 1964.

LONGHI, S.J. A estrutura de uma floresta natural de Araucaria angustifolia (Bert.) O. Ktze, no sul do Brasil. Curitiba: UFPR, 1980. 198p. Dissertação (Dissertação de Mestrado em Engenharia Florestal - Universidade Federal do Paraná).

MATTEUCCI, S. D.; COLMA, A. Metodologia para el estudio de la vegetacion. Washington: The General Secretarial of the Organization of American States, 1982. 167p. (Série Biologia. Monografia, 22).

MORENO, J.A. Clima do Rio Grande do Sul. Porto Alegre: Secretaria de Agricultura, 1961. 42p.

NEGRELLE, R.A.B.; SILVA, F.C. da. Fitossociologia de um trecho de floresta com Araucaria angustifolia (Bert.) O. Ktze. no município de Caçador - SC. Bol. Pesq. Florestal. Colombo, n.24/25, p.3754, 1992. 
OLIVEIRA, Y,M.M.; ROTTA, E. Levantamento da estrutura horizontal de uma mata de araucária no primeiro planalto paranaense. Bol. Pesq. Florestal. Colombo, n.4, p.1-45, 1982.

REVISTA DA MADEIRA. Rio Grande do Sul registra aumento de nativas. Curitiba: Associação Brasileira de Produtores de Madeira, n.57, p.40-42, 2001.

SANQUETTA, C.R.; DALLA-CORTE, S. Composição florística, estrutura e dinâmica de um fragmento florestal com Araucaria angustifolia no sudoeste paranaense. Rev. Acadêmica, Curitiba, n.1, p.3-28, 1998.

SCHNEIDER, P.R.; GALVÃO, F.; LONGHI, S.J. Influência do pisoteio de bovinos em áreas florestais. Floresta, Curitiba, v.9, n.1, p.1923, 1978.

SHEPHERD, G.J. FITOPAC 1: manual do usuário. Campinas: UNICAMP. Departamento de Botânica, 1994. 9p.

SOLÓRZANO-FILHO, J.A; KRAUS, J.E. Uma breve história das Matas de Araucária. Eco 21: Rio de Janeiro, n.48, p.37-40, 2000.

LUCIANO FARINHA WATZLAWICK luciano_farinha@uol.com.br

Rubens Marques Rondon Neto rrondon@floresta.ufpr.b

Marcos Vinícius Winckler Caldeira caldeira@floresta.ufpr.br

EMERSON Roberto Schoeninger emerson@floresta.ufpr.br

Centro de Ciências Florestais e da Madeira Universidade Federal do Paraná Curitiba, PR - Brasil 